\title{
Okavango Basin - Earth Observation
}

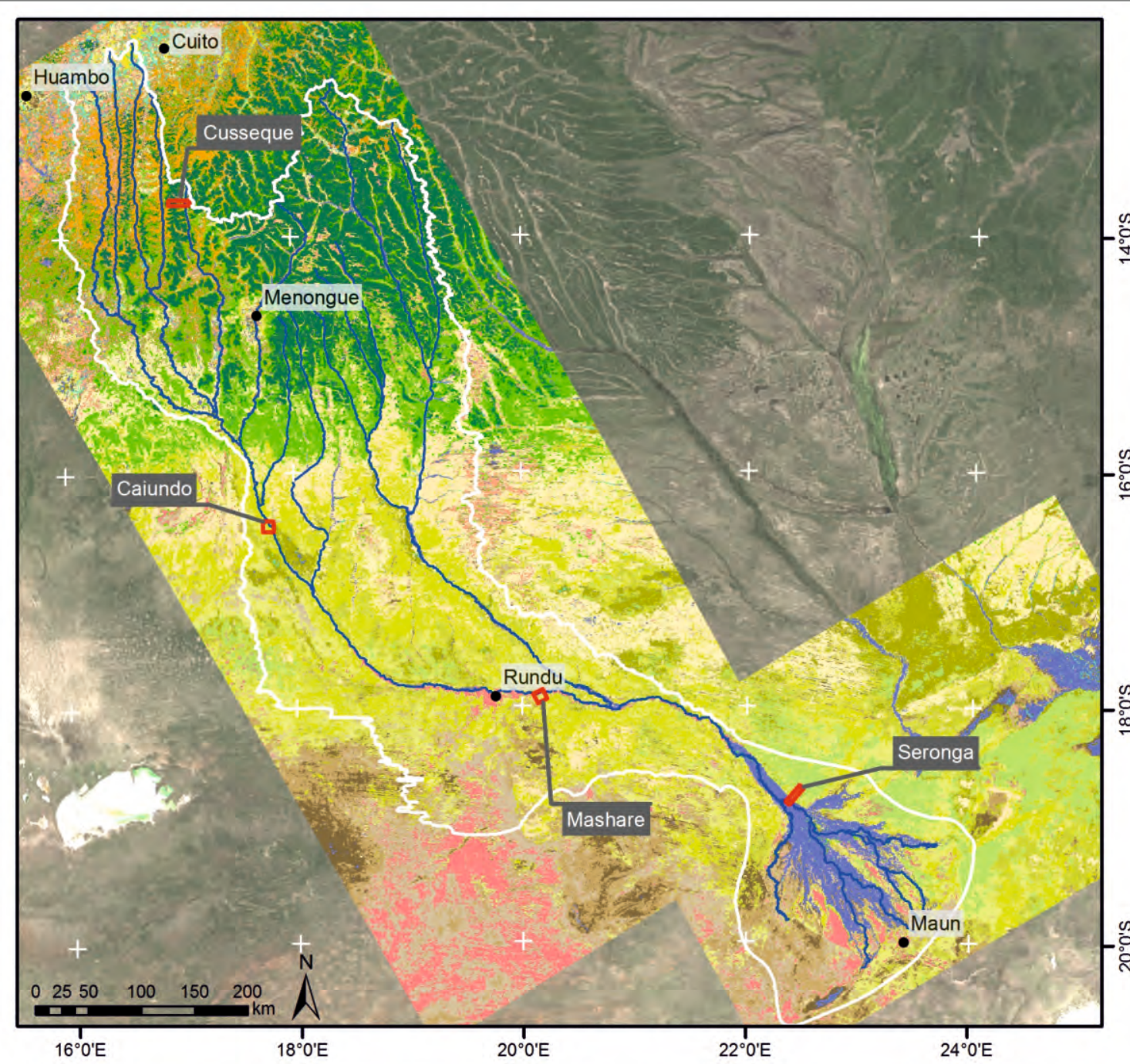

Dominant land cover

Thornbush savannah dominated by Acacia spp.

Forests and woodlands

\section{Miombo forests}

Miombo forests with Cryptosepalum exfoliatum ssp. pseudotaxus

Miombo forests dominated by deciduous tree species Miombo forests dominated by Julbernardia paniculata

Woodlands on Kalahari sand

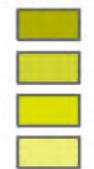

\section{Baikiaea-Burkea woodlands (dense)}

Baikiaea-Burkea woodlands (medium dense)

Baikiaea-Burkea woodlands (open)

Mixed Burkea woodlands (with Terminalia sericea)

Other woodlands

Mixed woodlands (including Colophospermum mopane)

Open and degraded woodlands (on sandy soils)

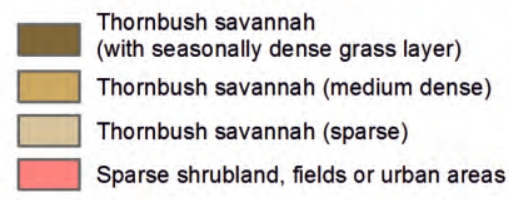

Shrub- and grasslands

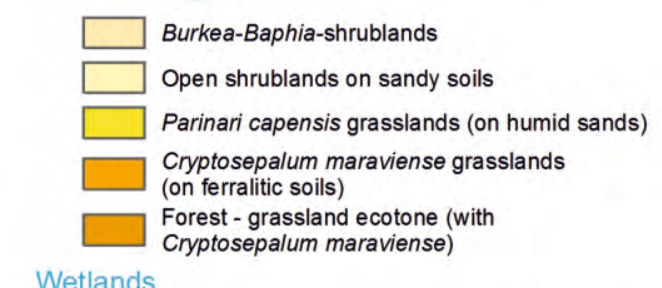

Seasonally flooded grasslands and reedbeds

Wet grasslands and peatlands

Additional information Okavango Catchment

FORA

Core sites

- Cities m Main rivers

Data source/background

The classfication is based on phenology parameters that were derived with the software package

TIMESAT (Jönsson and Eklundh 2002) based on the MODIS 16-day EVI product (MOD13Q1) courtesy of EOSDIS-NASA.

Projection/Datum:

UTM, WGS 1984

Zone $34 \mathrm{~S}$

Fig. 1: Dominant land cover classes produced by an unsupervised classification approach which was based on phenology metrics derived from 16-day MODIS EVI time series covering the observation period 2000 to 2011. 
Table 1: Proportions of dominant land cover types within the FORA (Future Okavango Research Area).

\begin{tabular}{|c|c|c|}
\hline Land cover class & Area $\left(\mathrm{km}^{2}\right)$ & Percent \\
\hline Miombo forests & 58,752 & 25.76 \\
\hline Miombo forest with Cryptosepalum exfoliatum ssp. pseudotaxus & 29,811 & 13.07 \\
\hline Miombo forest dominated by deciduous tree species & 13,805 & 6.05 \\
\hline Miombo forest dominated by Julbernardia paniculata & 15,135 & 6.64 \\
\hline Woodlands on Kalahari Sands & 68,046 & 29.83 \\
\hline Baikiaea-Burkea woodlands (dense) & 3,417 & 1.50 \\
\hline Baikiaea-Burkea woodlands (medium dense) & 16,512 & 7.24 \\
\hline Baikiaea-Burkea woodlands (open) & 28,377 & 12.44 \\
\hline Mixed Burkea woodlands (with Terminalia sericea) & 19,741 & 8.65 \\
\hline Other woodlands & 15,365 & 6.74 \\
\hline Mixed Kavango woodlands (including Colophospermum mopane) & 7,526 & 3.30 \\
\hline Open and degraded woodlands (on sandy soils) & 7,839 & 3.44 \\
\hline Thornbush savannah & 29,177 & 12.79 \\
\hline Thornbush savannah (with seasonally dense grass layer) & 3,641 & 1.60 \\
\hline Thornbush savannah (medium dense) & 9,612 & 4.21 \\
\hline Thornbush savannah (open) & 10,161 & 4.45 \\
\hline Sparse shrublands, fields or urban areas & 5,763 & 2.53 \\
\hline Shrub- and grasslands & 40,098 & 17.58 \\
\hline Burkea-Baphia shrublands & 17,069 & 7.48 \\
\hline Open shrublands on sandy soils & 13,141 & 5.76 \\
\hline Parinari capensis grasslands (on humid soils) & 738 & 0.32 \\
\hline Cryptosepalum maraviense grasslands (on ferralitic soils) & 4,595 & 2.01 \\
\hline Forest grassland ecotone (with Cryptosepalum maraviense) & 4,555 & 2.00 \\
\hline Wetlands & 16,667 & 7.31 \\
\hline Seasonally flooded grasslands and reedbeeds & 12,906 & 5.66 \\
\hline Wet grasslands and peatlands & 3,761 & 1.65 \\
\hline Total & 228,104 & 100.00 \\
\hline
\end{tabular}

Based on the Moderate Resolution Imaging Spectroradiometer (MODIS) earth observation time series, phenological parameters were derived for the Okavango Catchment covering the time period from July 2000 to July 2011 at a pixel resolution of $250 \mathrm{~m}$ by $250 \mathrm{~m}$. This analysis was based on 16-day-composites of the Enhanced Vegetation Index (EVI) that is related to vegetation cover and density (Fig. 1 of the Electronic Appendix; Jönsson \& Eklundh 2002). According to the information gathered from the phenological analysis, an unsupervised classification was performed to identify the spatial patterns of major functional vegetation types within the observation period. The nomenclature of the resulting 20 classes was performed knowledgebased on extensive field work in the Okavango region aiming at identifying the dominant vegetation type that each class represents. The resolution of MODIS and as well the limited number of 20 classes includes the shortcoming that the actual vegetation cover might locally differ from the nomenclature in the map.

The land cover map (Fig. 1) shows a gradient in land cover classes from the upper catchment with high rainfall amounts compared to the downstream areas. The northern part of the catchment is dominated by Miombo woodlands. These woodlands are traversed by river valleys feeding the tributaries of the Okavango River. Open grasslands, often accompanied by dwarf shrubs, dominate these valleys. The middle reaches are characterized by extensive woodlands on Kalahari sand. The delta area with low precipitation is surrounded by mixed woodlands on the eastern side (including Terminalia and Mopane), whereas on the western side thornbush savannah represents the main vegetation type. The Okavango Panhandle and Delta form a special ecosystem. Here, land cover is governed by inundation rather than the amount of rainfall and is dominated by seasonally flooded grasslands and reedbeds. Table 1 summarizes the proportion of each dominant land cover class.

An important landscape forming factor is the fire regime. Based on the MODIS burned area product that provides regular information on fires since April 2000, fire frequency (Fig. 2) as well as the main season of fire occurrence (Fig. 3) were calculated for the entire catchment. Fires are occurring in most parts of the catchment (Fig. 2), being most frequent in the fluvial valleys of the upper catchment as well as in the savannah regions. In Miombo forests and large parts of the Okavango Delta, fires are infrequent or even non-existent during the observation period. In Angola, the fires in the river valleys are mainly occurring in June/July whereas the main fire season in the savannah is August to September (Fig. 3). If the Miombo forests are affected by fires, these are usually occurring from September to October. 


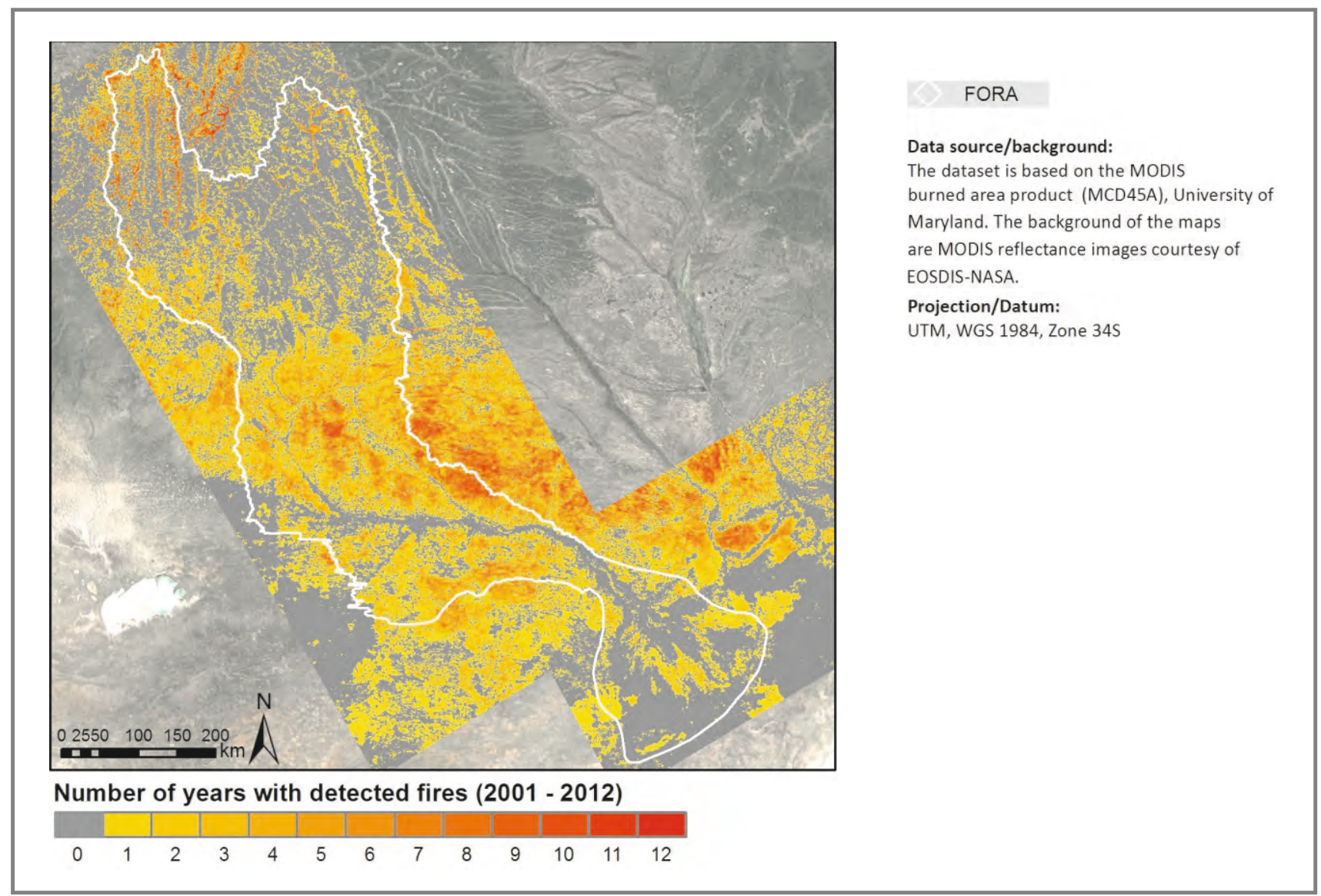

Fig. 2: Number of years with detected fires within the observation period 2001 to 2012 . The map is based on the burned area product (MCD45A).

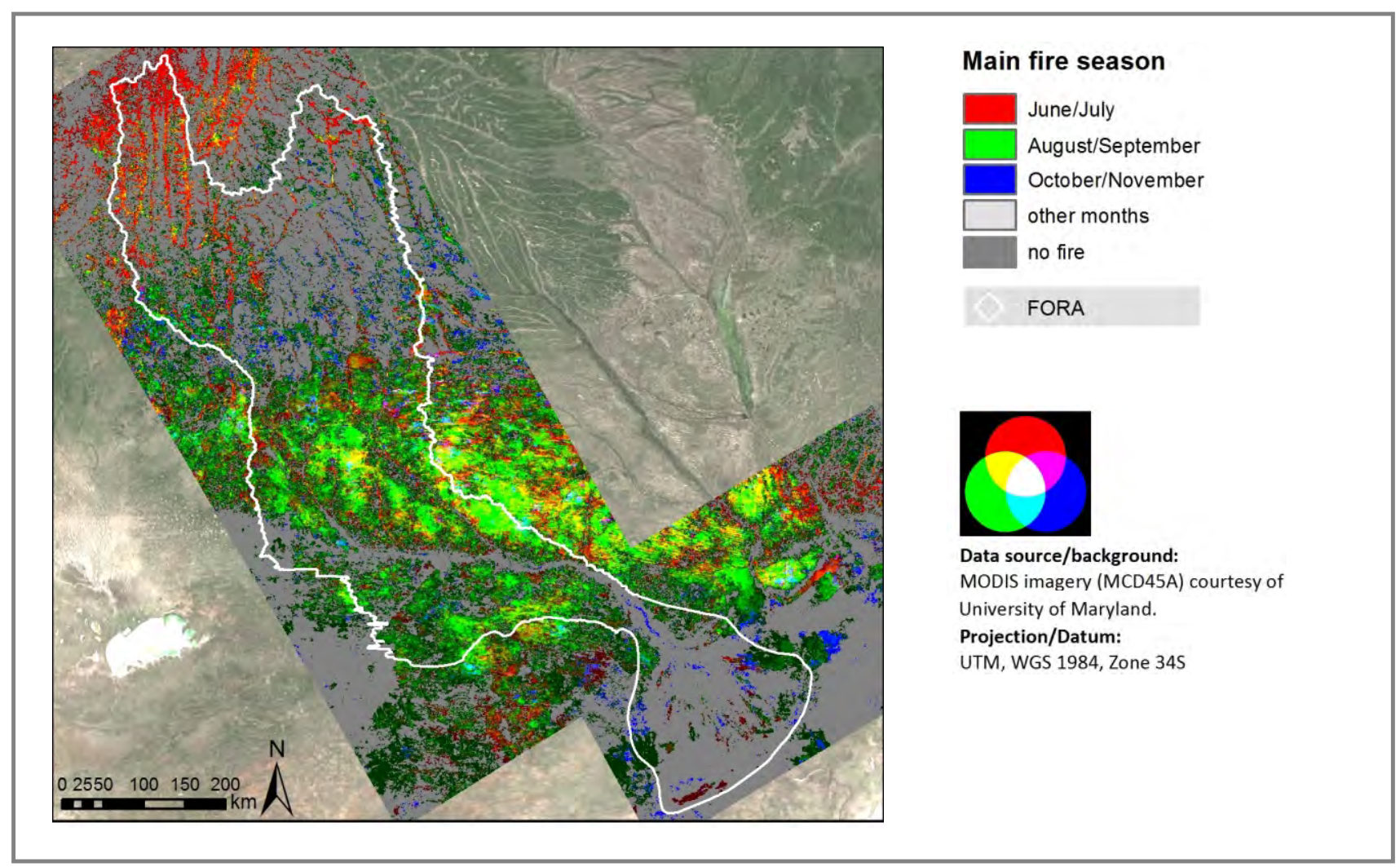

Fig. 3: Main fire season within the FORA covering the observation period 2001 to 2012 . The main fire season is illustrated as a RedGreen-Blue (RGB) false colour composite, where red colours correspond to the main fire season in June/July, green colours in August/September and blue colours in October/November. Yellowish and cyan colours result from the combined occurrence of fires in different periods, where yellow results from fires in the period June to September and green colours from fires during August to November. The brightness of the colours is related to the frequency of fire events. The product is based on the burned area product (MCD45A). 


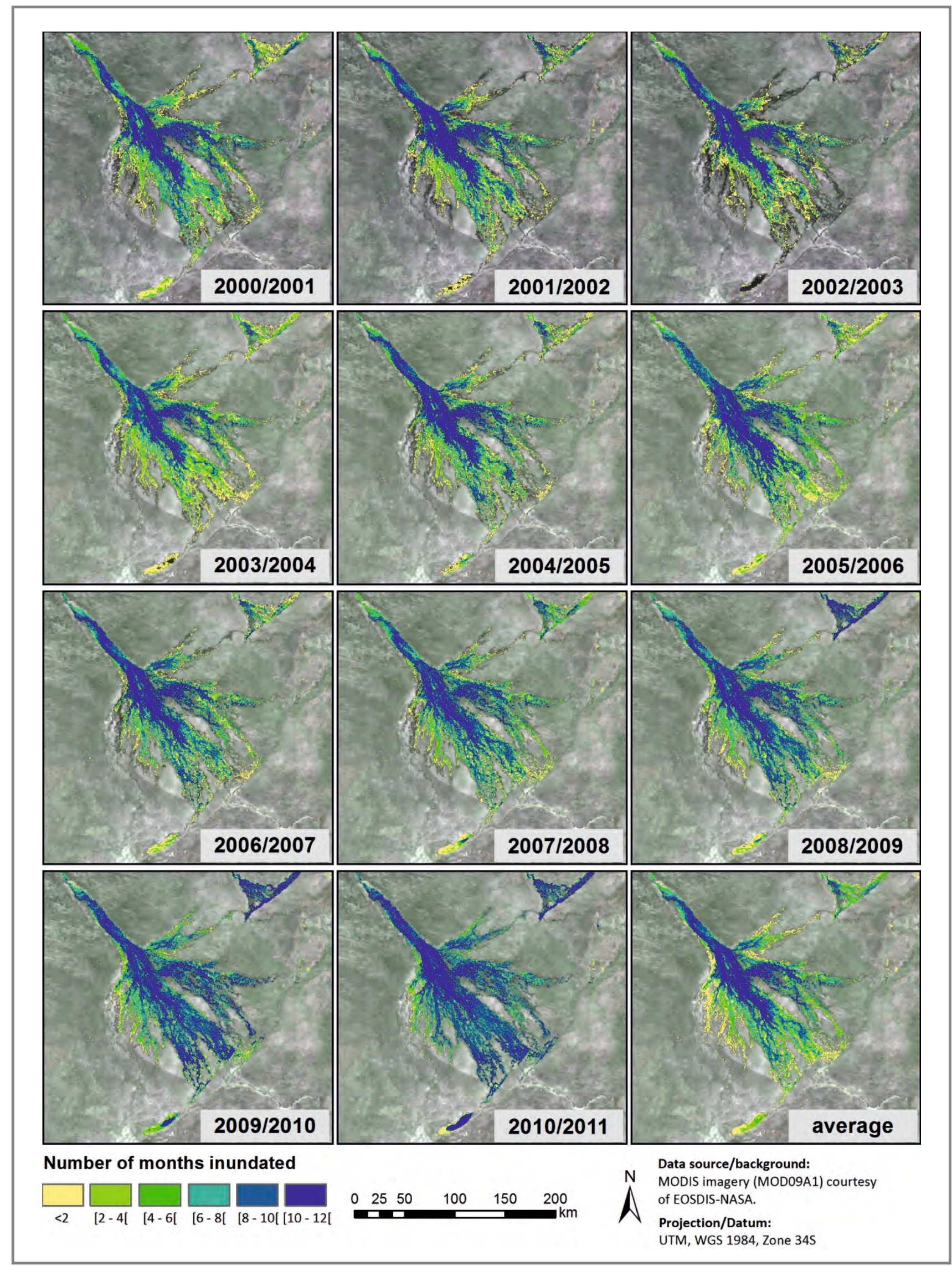

Fig. 4: Estimated number of months inundated within the Okavango Panhandle and Catchment covering the observation period from 2000 to 2011. The dataset is based on 8-day reflectance data of the MODIS sensor (MOD09A1). 
Inundation of the Delta (Fig. 4) was monitored by implementing an expert based decision tree derived from a time series of MODIS reflectance data (MOD09A1) similar as described by Murray-Hudson (2009). Problems can arise when inundated areas are also densely vegetated, because the spectral mixture impedes the mapping of the flooding extent. The inundation map shows the annual duration of the flooding from $2000 / 2001$ to $2010 / 2011$ as well as its overall mean. The annual maps (Fig. 4) show that the duration of inundation is spatially very different. Moreover, there is a marked interannual variation in the extent of the overall flooded area. Mean inundation area of the Panhandle and Delta as derived with the implemented method is around $9,000 \mathrm{~km}^{2}$. Rainfall was abundant in the years 2009-2010 (Weber 2013) and during that period Lake Lage Ngami, close to the southern margin of the presented subset to be permanently flooded again.

\section{Acknowledgements}

This study was funded by the BMBF (The Future Okavango project). For details see authors' general acknowledgements in this volume.

\section{References}

Jönsson, P., and Eklundh, L. (2002): Seasonality extraction by function fitting to time-series of satellite sensor data. IEEE Transactions on Geoscience and Remote Sensing 40: 1824-1832. CrossRef

Murray-Hudson, M. (2009): Floodplain Vegetation Responses to flood regime in the seasonal Okavango delta, Botswana. - PhD thesis: University of Florida. http://etd.fcla.edu/UF/UFE002 4728/murrayhudson_m.pdf.

Weber, T. (2013): Okavango Basin Climate. - Biodiversity \& Ecology 5. CrossRef

Responsible authors: M. Stellmes, D. Frantz, M. Finckh, R. Revermann 
